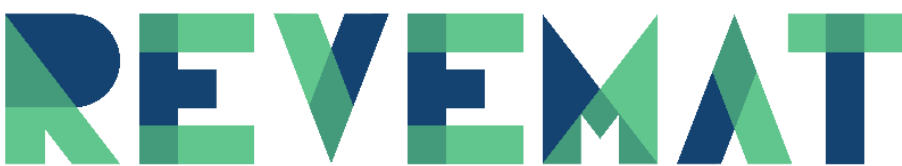

REVISTA ELETRÔNICA DE EDUCAÇÃO MATEMÁTICA

\title{
AMBIENTES DE APRENDIZAGENS VERSUS APRENDIZAGEM SIGNIFICATIVA. UMA ANÁLISE DE PRÁTICAS DESENVOLVIDAS NA FORMAÇÃO DE PROFESSORES DE MATEMÁTICA EM BENGUELA-ANGOLA Learning environments versus meaningful learning. An analysis of practices developed in the training of mathematics teachers in Benguela-Angola
}

Alberto Domingos Jacinto QUITEMBO Universidade Katyavala Bwila, Benguela, Angola jquitembo50@gmail.com

(D) http://orcid.org/0000-0002-7724-8886

A lista completa com informações dos autores está no final do artigo

\begin{abstract}
RESUMO
Os ambientes de aprendizagem constituem contextos de interação entre o professor e alunos e alunos entre si, quando adequadamente concebido pelo professor. O envolvimento dos alunos na realização das tarefas marca a essência dos ambientes de aprendizagem, animado pelo diálogo, mediado pelo professor, que procura explorar e desenvolver as capacidades dos alunos para conjecturar, argumentar, concluir, validar, avaliar, a partir dos quais constrói e assimila novos significados, tornando a aprendizagem consciente e significativa. No entanto, a sua criação depende do modo como o professor os concebe, podendo favorecer ou desfavorecer o desenvolvimento da aprendizagem significativa. No entanto, a ação do professor em sala de aula pode ser o reflexo das aprendizagens decorrentes da formação, no qual, as experiências do formador, sobretudo na fase de práticas influencia as práticas profissionais dos futuros professores. Assim, olhando para a formação de professores de Matemática, sobretudo, na fase da prática pedagógica, se formula a seguinte questão: as experiências transmitidas aos futuros professores na realização da prática pedagógica, asseguram a implementação pelos futuros profissionais de ações que promovam a aprendizagem significativa nos seus alunos? Pretende-se perceber se as práticas formativas desenvolvidas propiciam o desenvolvimento da aprendizagem significativa e se podem constituir experiências para os futuros professores na realização da atividade profissional.

$O$ estudo seguiu a abordagem qualitativa de natureza descritiva e interpretativa, cujos resultados mostram o desenvolvimento de um ensino centrado na memorização, enquadrado no modelo tradicional de ensino e aprendizagem, em detrimento da aprendizagem significativa.
\end{abstract}

Palavras-chaves: Ambientes de aprendizagem, Aprendizagem significativa, Prática pedagógica, Orientador/supervisor.

\section{ABSTRACT}

Learning environments are contexts of interaction between the teacher and students and students among themselves, when properly conceived by the teacher. The involvement of students in the realization of tasks marks the essence of learning environments, animated by dialogue, mediated by the teacher, who seeks to explore and develop the skills of students to conjecture, argue, conclude, validate, evaluate, from which it builds and assimilates new meanings, making learning conscious and meaningful. However, their creation depends on how the teacher conceives them, and may favor or disadvantage the development of meaningful learning. However, the teacher's action in the classroom may be a reflection of the learning stemming from the training, in which the experiences of the trainer, especially in the practice phase, influence the professional practices of future teachers. Thus, looking at the training of mathematics teachers, especially in the phase of pedagógical practice, the following question is formulated: do the experiences transmitted to future teachers in the realization of pedagógical practice, ensure the implementation by future professionals of actions that promote meaningful learning in their students? It is intended to understand whether the training practices developed favor the development of meaningful learning and can constitute experiences for future teachers in the performance of 
professional activity. The study followed a qualitative approach of descriptive and interpretative nature, whose results show the development of a teaching centered on memorization, framed in the traditional model of teaching and learning, to the detriment of meaningful learning.

Keywords: Learning environments, Meaningful learning, Pedagógical practice, Advisor/supervisor.

\section{INTRODUÇÃO}

Os constrangimentos decorrentes do processo de ensino-aprendizagem da Matemática apontam como razão, as debilidades dos alunos na aprendizagem, talvez pelo seu papel passivo, conformado pelo ensino tradicional, mais focalizado na memorização (Quitembo, 2010). A atitude do aluno face a aprendizagem depende do modo como o professor organiza e estimula a aprendizagem dos conteúdos matemáticos, o que define o seu nível de envolvimento na realização das tarefas. Assim, tal como recomenda o National Council of Teachers of Mathematics (NCTM), "o ensino deve ser organizado em torno da procura de soluções para os problemas e deve incluir constantes oportunidades para falar acerca da matemática" (NCTM, 1994, p. 131). Isso implica diálogo entre o professor e os alunos na negociação dos significados, de forma a incluílos de modo consciente no seu campo cognitivo. Deste modo, os ambientes criados devem tornar o aluno ativo na construção de significados, na assimilação consciente das vitórias e derrotas académicas. A instituição de formação de professores tem sido objeto de estudos focalizados no modo como os formadores orientam o processo formativo, as suas práticas, bem como o modelo formativo adotado para a formação de professores. Neste sentido, o estudo realizado por Quitembo (2010) mostrou que a prática dos professores estavam enquadradas no modelo tradicional de ensino. Os resultados inspiraram a realização de um estudo centrado nos modos de orientação ${ }^{1}$ e supervisão ${ }^{2}$ adotado pelos professores durante a realização da prática pedagógica. Se elegeu como foco de estudo, os ambientes de aprendizagem criados pelo professor numa perspetiva de desenvolvimento da aprendizagem significativa, assentes no seguinte problema: as experiências transmitidas aos futuros professores na realização da prática pedagógica asseguram a implementação pelos futuros profissionais de ações que promovam a aprendizagem significativa nos seus alunos? Pretendeu-se perceber se as práticas de orientação e de supervisão propiciam o desenvolvimento da aprendizagem significativa e

\footnotetext{
${ }^{1}$ Desenvolvido pelo professor da escola de prática (estágio) responsável por um grupo de praticantes.

2 Desenvolvido pelo professor de prática pedagógica na instituição de formação de professores.
} 
se podem constituir experiências a serem usadas pelos futuros professores na realização da atividade profissional. O estudo esteve focalizado nos modos de atuação do professor orientador/supervisor da prática pedagógica em relação ao discurso na sala de aula, as tarefas matemáticas e as formas de organização dos alunos, como aspetos fundamentais para o envolvimento dos alunos na realização das tarefas.

\section{REVISÃO DE LITERATURA}

\subsection{Ambientes de aprendizagem}

O ambiente de aprendizagem pode traduzir-se no maior ou menor envolvimento no trabalho e uma maior rigidez ou informalidade nas relações entre os intervenientes do processo de ensino-aprendizagem. O mesmo está condicionado e é influenciado pela relação de poder estabelecida e pelos papéis atribuídos aos alunos e ao professor (Ponte, Boavida, Graça, \& Abrantes, 1997). Segundo os autores, as tarefas propostas pelo professor e a maneira como gere a comunicação e negociação de significados, assume o papel preponderante no processo de ensino-aprendizagem. Isso significa, que o professor deve conceber e estabelecer a cultura que deve reinar na sala de aula, na qual, o modo de trabalho dos alunos a partir das diferentes formas de interação, deve definir o estatdo de envolvimento dos alunos e do professor, de acordo com as suas conceções e crenças.

No entanto, tal como sublinha Serrazina (2002), a forma como o professor encara a Matemática e a forma de organizar a sala de aula influencia o aluno na construção das suas histórias de aprendizagem. Logo, as relações estabelecidas e os papéis dos intervenientes no processo de ensino-aprendizagem determinam a cultura reguladora de comportamento e de interação na sala de aula, bem como estimulam as expetativas dos respetivos intervenientes na aprendizagem. Assim, a cultura da sala de aula deve ser reforçada pelo "tipo de tarefas que o professor propõe, o modo como encoraja (ou não) a manifestação de dúvidas e opiniões dos alunos baseados na argumentação" (Ponte et al., 1997, p. 91). Estes aspetos transmitem explicita ou implicitamente "o papel que o professor atribui aos alunos na aprendizagem e sobre as suas expetativas em relação às suas capacidades" (p. 91).

Igualmente, o uso de materiais auxiliares (calculadora, computador e outros meios didáticos) possibilitam o desenvolvimento de um ambiente de trabalho participativo, para o 
qual o professor deve reforçar o domínio do discurso, de modo a estimular nos alunos atitude crítica e investigativa, que enriquece a sua capacidade de raciocínio e de comunicação (NCTM, 1994; Ponte et al., 1997; Serrazina, 2002; Precatado et al., 1998). Para Precatado, Lopes, Baeta, Loureiro, Ferreira, Guimarães \& Abrantes (1998, p. 43), “a aprendizagem dos alunos pode reforçar-se com a utilização de materiais que proporcionem o seu forte envolvimento, nomeadamente, materiais manipuláveis, calculadoras e computadores". No entanto, a aprendizagem dos conteúdos matemáticos é favorecida pelo ambiente de aprendizagem construído, se os alunos forem capazes de se reconhecerem como uma comunidade de pessoas que colaboram entre si, a fim de que as ideias matemáticas tenham sentido. Nesta ordem, o NCTM (1994) e Ponte et al. (1997) consideram que os alunos podem trabalhar de forma individual e em seguida comparar os resultados entre si, ou podem trabalhar em pares ou em pequenos grupos, desde que, orientados e modelados pelo professor.

A discussão com todo o grupo é um dos aspetos que apresenta largas vantagens para a aprendizagem dos alunos. O trabalho coletivo constitui uma estratégia importante no ensino da Matemática, sobretudo, quando é utilizado na apresentação de nova matéria, em que a negociação de significados matemáticos exige questionamentos e participação ativa dos alunos no tratamento do conteúdo (Ponte et al., 1997). Mas, segundo os autores, o exagero no seu uso (quando ocupa todo o tempo da aula), pode levar muitos alunos a distraírem-se e a deixarem de participar, não permitindo assim, "o desenvolvimento de determinado tipo de competências e capacidades que exigem esforço individual ou interação com outros colegas" (p. 92). O importante é que as discussões estejam conjugadas com outras formas que facilitem o envolvimento de todos os alunos (Ponte et al., 1997). Neste sentido, importa prestar-se mais atenção à situações variadas de trabalho, com formas diversificadas de interação em aula, com especial realce para situações de discussão entre os alunos na realização de trabalho de grupo (Precatado et al., 1998), nas diversas tarefas, particularmente a resolução de problemas e de trabalho de projeto. Isto implica a capacidade do professor valorizar as ideias dos alunos, encorajá-los a dar contribuições e respeitar as diferenças e dificuldades (NCTM, 1994; Ponte et al., 1997).

O ambiente de aprendizagem constitui assim a via favorecedora do desenvolvimento do poder matemático dos alunos, consubstanciado no desenvolvimento do raciocínio matemático e das competências de todos os alunos, bem como a sua predisposição face à Matemática (NCTM, 1994). Segundo o autor, a sua natureza é 
modelada pelo tipo de atividade matemática e pelo discurso em que os alunos se envolvem e as aptidões dos professores para desenvolver e integrar as atividades, discurso e ambiente, de forma a promover a aprendizagem dos alunos. Para o efeito, é importante que o professor esteja atento nas formas de representar, pensar, falar, concordar ou discordar que os alunos usam para se envolver no processo de ensino e aprendizagem. Ou seja, estes elementos constitutivos do discurso determinam a interação estabelecida entre alunos e professor, com as quais se ajustam os significados entre os diversos intervenientes na sala de aula, através da linguagem comum e da linguagem matemática.

A maneira como os alunos e professores expressam o seu entendimento sobre os conceitos e processos matemáticos, tendo sempre em conta as experiências e conhecimentos que possuem, torna a negociação de significados um aspeto importante na aprendizagem dos alunos (Ponte et al., 1997). Segundo os autores, na partilha de significados, a negociação deve ser feita tendo em conta a necessidade de questionar e responder às questões, dar razão e pedir razões, clarificar e pedir clarificações, dar analogias e pedir analogias, descrever e pedir descrições, dar e receber exemplos. Cada interveniente deve clarificar a razão presente na questão em negociação para sua validação, e isso significa que o professor deve encarar as explicações como objetos de aprendizagem. Para o efeito, tem a responsabilidade de estabelecer um clima na sala de aula que proporcione oportunidades para os alunos explorarem as suas próprias ideias e as dos outros, individual e coletivamente, sem medo do ridículo ou de sanções" (Hewson, 2001, p. 121), permitindo-Ihe conhecer e acompanhar a evolução dos alunos. Para isso, na perspetiva de Ponte et al. (1997) é preciso que o professor crie oportunidades para a participação dos alunos, colocando questões e propondo tarefas que facilitem, promovam e desafiem o pensamento de cada aluno. É preciso que o professor saiba ouvir com atenção as ideias dos alunos e pedir-lhes que as clarifiquem e justifiquem, oralmente ou por escrito.

A atividade matemática é integrada por tarefas como projeto, questões, problemas, construções, aplicações e exercícios em que os alunos se envolvem (NCTM 1994), cujo propósito está focalizado no desenvolvimento do poder matemático. Na perspetiva do autor, o poder matemático corresponde as capacidades matemáticas variadas, e o sentimento de autoconfiança na resolução e formulação de problemas, no raciocínio lógico e na comunicação em Matemática, bem como, na capacidade de explorar situações e de identificar regularidades, na capacidade de formular e testar conjeturas, e 
na capacidade de valorizar a Matemática e a de relacionar com aspetos contextuais ( $p$. 149).

Os professores, para além de seleccionarem exercícios e problemas constantes nos livros de textos, programas de computadores, materiais manipuláveis, calculadoras, e outros, devem elaborar com frequência as suas próprias tarefas para os alunos, das quais, o NCTM (1994) destaca, por exemplo: projeto, problemas, fichas de trabalho, etc. $\mathrm{Na}$ escolha e construção de propostas de trabalho para os alunos, o professor deve ter em atenção aquelas que promovem nos alunos o desenvolvimento da compreensão dos conceitos e dos processos, de modo a estimular em simultâneo a capacidade de resolver problemas, de raciocinar e de comunicar matematicamente. Para tal, é necessário ter-se em atenção a natureza das atividades que os alunos deverão desenvolver, porquanto a aprendizagem da Matemática deve ser encarada como produto da atividade, e não se reduzir na resolução repetitiva de exercícios de aplicação de certas fórmulas (APM, 1988).

Para a apropriação de novas ideias e novos conhecimentos não basta que o aluno participe em tarefas concretas, é preciso que ele se envolva num processo de reflexão sobre essa tarefa. Isto requer a seleção adequada de tarefas, muito em particular aquelas que não separam o pensamento matemático dos conceitos matemáticos ou aptidões, que despertam a curiosidade dos alunos e que os convidam a especular e a prosseguir com as suas intuições (NCTM, 1994). Para o efeito, na seleção, adaptação e criação das atividades matemáticas, os professores devem ter em conta os conteúdos matemáticos, os alunos e as suas formas de aprendizagem, pois, é a partir destas variáveis que deverá orientar as suas decisões (Vale, 2000) no que tange ao grau de dificuldade do conteúdo, o nível de rotina, de complexidade e de abertura da tarefa.

Algumas tarefas envolvem os alunos na simples produção de respostas corretas, enquanto outras exigem que o aluno especule, que pesquise alternativa, que decida se as suas abordagens são ou não válidas (NCTM, 1994). Para o autor, os professores devem avaliar até que ponto o conteúdo matemático presente na tarefa desenvolve aptidões e automatismos apropriados. Logo, o conteúdo é um aspeto crucial a ter em consideração na avaliação do valor de uma determinada atividade. No entanto, o conhecimento dos alunos, sobre o que já sabem e podem fazer, e até que ponto parecem preparados para crescerem inteletualmente, deve constituir preocupação do professor. Nesta perspetiva, o professor deve selecionar atividades que proporcionem oportunidades para conhecer melhor o pensamento e compreensão dos alunos, ao mesmo tempo que lhes estimula a ir mais além. Isso permite-lhe conhecer as confusões ou ideias erróneas dos alunos sobre 
um determinado conteúdo (NCTM, 1994), bem como, ajuda-o a selecionar tarefas que envolvam os alunos na exploração das ideias essenciais que muitas vezes estão na causa das confusões.

\subsection{Aprendizagem significativa}

A aprendizagem significativa decorre quando o professor explora o(s) fracasso(s) dos alunos na tentativa de compreender a causa, e procurar corrigí-los a medida que elabora conjeturas e testa os resultados através de inferências, comparações e analogias, bem como refletir sobre outras expetativas a partir de outros elementos introduzidos pelo professor (Klausen, 2003). Este processo tem validade se os conhecimentos prévios dos alunos são valorizados e tidos em conta como a via para a construção do novo conhecimento. Para o efeito, o uso de diferentes processos em que os alunos se envolvem deve ser visto como oportunidade para a "descoberta e redescoberta de outros conhecimentos, viabilizando uma aprendizagem que dê prazer a quem ensina e a quem aprende e também que tenha eficácia" (Ausubel, 1982, citado por Klausen, 2003).

A aprendizagem significativa traduz a capacidade dos alunos através da qual as "ideias expressas simbolicamente interagem de maneira substantiva e não-arbitrária com aquilo que o aprendiz já sabe" (Moreira, 2010). Rogers (2001) entende-a como uma aprendizagem além da acumulação de fatos. Aquela que provoca modificação no comportamento do indivíduo, na orientação futura que escolhe ou nas suas atitudes e personalidade, que não se limita a um aumento de conhecimento mas que atinge profundamente todas as parcelas da sua existência. Para Klausen (2003), é uma aprendizagem focalizada na compreensão de significados, a partir de experiências anteriores e vivências pessoais dos alunos. A mesma baseia-se na (re)formulação de problemas de algum modo desafiantes que incentivem 0 aprender mais, 0 estabelecimento de diferentes tipos de relações entre fatos, objetos, acontecimentos, noções e conceitos, bem como, modificações de comportamentos. A aprendizagem significativa "é o processo por meio do qual novas informações adquirem significado por interação (não associação) com aspectos relevantes preexistentes na estrutura cognitiva" (Moreira, 2006, p. 38).

Para o efeito, segundo o autor, é preciso que o professor estabeleça momentos de discussão, de auscultação de ideias e de experiências em que os alunos se envolvem. 
Isso significa que o seu envolvimento numa determinada tarefa denuncia algum interesse na sua realização e consequentemente na aprendizagem consciente do conteúdo. Nesta senda, para que a aprendizagem tenha lugar de modo consciente, Santos (2008, p. 33) alerta ao professor a ter em conta quatro condições básicas: i) a motivação; ii) o interesse; iii) a habilidade de compartilhar experiências e; iv) a habilidade de interagir com os diferentes contextos. Para Paula \& Bida (2008), estas condições colocam ao professor o desafio de despertar motivos para a aprendizagem, que ocorre através da seleção de conteúdos relevantes que tornem as aulas interessantes para os alunos. Segundo os autores, para que a aprendizagem significativa tenha lugar, as condições devem desafiar o professor a adotar a postura de mediador entre o aluno e o conhecimento, e a sua atuação deve estar focalizado no aluno como sujeito do conhecimento e não como mero receptor de informações.

Para o efeito, o professor a partir da planificação da aula deve ter em atenção a elaboração de questões que estimulem o aluno na busca e na exercitação das várias possibilidades de resposta como elementos que conduzem à aprendizagem significativa (Paula \& Bida, 2008). É necessário provocar o desejo de aprender, "problematizando o conteúdo, tornando-o interessante e não tirar o sabor da descoberta dando respostas prontas" (Santos, 2008). No entanto, se não se estimular o desejo de aprender, e se a aprendizagem não for significativa, o aluno activa os mecanismos de aprendizagem mecânica, baseado no decorar o conteúdo. Isto acontece, quando o papel do professor é apresentar o conteúdo, e os alunos limitam-se a copiar o texto, ou a responder as questões do professor (Paula \& Bida, 2008).

Contrariamente a essa prática, Ponte (1994), recomenda que o professor deve ter o conhecimento profundo do conteúdo que vai ensinar, o que lhe permite adotar as maneiras mais adequadas de as apresentar aos alunos de modo a facilitar a aprendizagem, as formas mais úteis de representação das ideias, as analogias mais importantes, as ilustrações, os exemplos, as exigências e demonstrações, a utilizar textos curtos (esquemas) e fazer questionamentos que conduzam à reflexão e participação dos alunos na construção do conhecimento. No entanto, para Paula e Bida (2008, citando Gasparin, 2001), na relação professor-aluno o professor não trabalha pelo aluno, mas com o aluno e, para o efeito, sugere: i) descobrir aquilo que é aprendizagem significativa para os alunos, pois se interessarão por aquilo que, de alguma maneira, os afetar diretamente; ii) envolver, através de técnicas variadas de ensino-aprendizagem, os educandos na reconstrução ativa do conhecimento sistematizado; iii) trabalhar com os 
alunos (e não pelos alunos); iv) adotar como forma de trabalho, o método dialético: prática-teoria-prática, onde a prática inicial consiste em conhecer, através de um diálogo com os alunos, as vivências cotidianas do conteúdo, antes de lhes ser apresentado na aula.

O segundo passo - a teoria, inicia-se por uma breve discussão sobre o conteúdo, buscando identificar as razões pelas quais ele merece ou precisa ser aprendido, problematizando-a tendo em conta as suas dimensões científica, conceitual, cultural, histórica, social, política e ética, para que os alunos elaborem uma síntese e assumam uma nova postura mental. A prática final expressa as intenções dos alunos sobre a possível aplicação do conteúdo aprendido e, quais as ações se propõem a realizar para que isso aconteça. Daí que, Klausen (2003, citando Libâneo, 1998, p. 29) considera o professor como mediador da relação ativa do aluno com a matéria, tendo em atenção o conhecimento, a experiência e o significado que o aluno traz à sala de aula, seu potencial cognitivo, sua capacidade e interesse, seus procedimentos de pensar e seus modos de trabalhar. Ensinar não significa, simplesmente, ir para uma sala de aula transmitir conhecimentos, mas é também um meio de organizar as atividades para que a criança aprenda e produza conhecimentos.

\subsection{Prática pedagógica na formação inicial de professores de matemática}

Uma Unidade de Ensino Potencialmente Significativa (UEPS) deve fazer uso de diversificados materiais e estratégias de ensino, de maneira a abandonar a narrativa do ensino centralizado no professor, em favor de um ensino centrado no aluno (Moreira, 2012). Para o efeito, o autor sugere como uma das estratégias do professor, começar o tratamento do conteúdo com uma breve exposição oral seguida de atividade colaborativa em pequenos grupos que, por sua vez, deve ser seguida de atividade de apresentação ou discussão em grande grupo. Logo, a UEPS é elaborada a partir de situações que levem o aluno a exteriorizar os seus conhecimentos prévios, a partir dos quais o professor apresenta o conteúdo, tendo em conta os princípios da diferenciação progressiva e da reconciliação integradora (Mendes, Santarosa \& Camargo, 2020, p. 4). Segundo os autores, a diferenciação progressiva é essencial para a aprendizagem significativa, pois tem lugar quando a abordagem de um conceito é feita partindo do geral para o específico, 
onde os significados mais pontuais sejam abordados após se apresentar as visões mais amplas e gerais do conhecimento.

Para a implementação dessas práticas é preciso que a prática do professor não se enquadre nos esquemas parametrizados de ensino, adotado e validado pelos especialistas (Ferreira \& Valente, 2020). Para eles, um novo profissional dotado de novo saber, que articule os saberes vindos dos campos disciplinares (saberes a ensinar) e aqueles que provêm das ciências da educação (saberes para ensinar), torna-se necessário. Deste modo, olhando para a formação de professores, se considera que as dinâmicas de organização dos saberes estão associadas à compreensão de como se articulam os saberes a ensinar e os saberes para ensinar (Valente, 2017). Entre estes dois campos do saber, o autor sublinha atribuir-se relevancia aos saberes a ensinar, vindo do campo disciplinar específico, que representam os fundamentos da profissão e sobre os quais se desenvolve a identidade profissional dos professores. Esta tendência, à medida que os saberes se diferenciam, as identidades profissionais dos professores sobre os saberes a ensinar se reforçam mais em detrimento dos saberes para ensinar, sendo este último tido como um aspecto relevante unificador em torno de uma profissão comum de professor (Valente, 2017, citando Borer, 2009). O saber para ensinar é "fruto de elaboração histórica do ofício docente, ferramenta acionada para melhor realizar o ofício de ensinar os saberes que a sociedade atribui à escola como sua função institucional" (Valente, 2017,p. 214). Segundo o autor, os saberes para ensinar são tidos como meios que deverão ser mobilizados pelo futuro professor para cumprir o seu ofício de ensinar, os meios que tranformam o saber a ensinar (objeto de trabalho docente) em um saber como instrumento de trabalho (ensinável).

Neste sentido, a formação inicial de professores deve ser desenvolvida na base de que o indivíduo é o agente construtor do seu próprio conhecimento, e que os significados por ele construídos a partir das suas experiências e vivências em diferentes contextos formem sentido e constituem representações da realidade. É a partir da interpretação que os formandos fazem da prática e dos contextos que ele atribui e compreende o novo papel do professor, cuja função básica é a de orientar o processo de (re)construção de significados pelo aluno, através da avaliação permanente, do suporte em termos de materiais a serem trabalhados, da motivação e interação constante, e da organização sistemática do processo.

Olhando para a escola e as suas contradições internas derivadas da luta entre a conservação de velhas práticas e a operacionalização de mudanças, em muitos casos, 
"apesar de ter seu quadro docente em constante renovação não pressupõe uma reformulação do seu corpo de saberes, dos seus procedimentos e métodos. Esta inércia conduz a uma cristalização dos princípios que regem a fragmentação" (Oliveira, 2002, p. 111). Daí que, segundo o autor, é impossivel analisar a formação de professores sem ter em conta a instituição formadora, sem olhar para os saberes transmitidos por ela, sem olhar para o professor enquanto individuo criativo que, antes, durante e após o processo de formação, projeta uma série de sentimentos, imagens e expetativas diante do "ser professor" (p. 112).

Um dos momentos em que a instituição, os professores e os formandos põem em evidência os saberes a ensinar e os saberes para ensinar é na realização da prática pedagógica. De acordo com Ponte et al. (2000), na orientação do processo de (re)construção de significados, é preciso ter em conta que o professor orientador/supervisor, bem como, os formandos têm as suas próprias conceções sobre como deve ser o ensino para chegar à aprendizagem. Deste modo, tal como refere Ponte (1994a), a formação depende do modo como a concebemos e, no entanto, ela pode favorecer ou dificultar a aprendizagem. Daí que, a implementação exitosa da prática pedagógica, independentemente das orientações para a sua realização, depende também da forma como a concebemos.

As novas tendências de orientação/supervisão da prática pedagógica apontam para uma conceção democrática e estratégica que valorizam a reflexão, a aprendizagem em colaboração, a capacidade de gerar, gerir e partilhar o conhecimento, a assunção da escola como comunidade reflexiva e aprendente capaz de criar para todos, condições de desenvolvimento e de aprendizagem (Alarcão \& Roldão, 2008). Logo, os caminhos para se alcançar este fim e o significado de aprendizagem refletem-se na sua prática pedagógica, através das estratégias adotadas para se trabalhar o conteúdo específico a ensinar, na escolha dos livros didácticos, nos critérios de avaliação, entre outros factores explícitos e implícitos, bem como das estratégias adotadas pelo orientador/supervisor.

O orientador e o supervisor devem proporcionar uma assistência ativa aos futuros professores, intermediando a construção de significados nas suas interpretações, em relação o contato com a escola, os professores, os artefatos que os professores utilizam e como valorizam as intervenções didático-educativas (Alarcão \& Roldão, 2008). Segundo os autores, o contacto "com a realidade da prática docente apresenta-se como provocador de questionamento e pesquisas, mobilizador de saberes, atribuidor de 
sentidos a saberes disciplinares anteriormente lecionados" (p. 28). Deste modo, descurar o papel e as competências do orientador e do supervisor pedagógicos é pôr em risco o processo de formação do futuro professor, baseado no(s) modelo(s) de formação, pois a qualidade da formação inicial centrada na escola e do tipo de reflexões implementadas e experimentadas, depende crucialmente do orientador/supervisor. Para o efeito, o supervisor/orientador precisa conhecer as teorias subjetivas dos processos de aprendizagem do formando para melhorar o seu desempenho em relação à comunicação, questionamento, sugestões, encorajamento e avaliação, permitindo conhecer o entendimento interpessoal emergido dos ambientes interativos de aprendizagem.

Os processos interativos de orientação/supervisão, no entender de Alarcão (1994) se desenvolvem em momentos de planificação (reflexão para a ação), de concretização (reflexão na ação) e na reflexão posterior à concretização (reflexão sobre a ação). Deste modo, a observação e a interação verbal, constituem estratégias fulcrais para um bom clima de colaboração e de encorajamento e, por isso, facilitadoras de reflexão posterior à ação, na medida em que, o formando, na base das observações, críticas e recomendações dos colegas e do supervisor/orientador, fará uma reflexão para o melhoria da sua prática (Alarcão \& Roldão, 2008). Para Alarcão (1994) o processo de supervisão/orientação através de processos de experimentação-reflexão-experimentação, estabelece gradualmente a necessária articulação entre a teoria e a prática e, deste modo, promove-se o desenvolvimento do futuro professor. No entanto, tal como refere Oliveira (2002, citando Tradif, 1999), apesar das instituições de formação manterem um corpo de saberes estruturados, tidos como indispensáveis à formação e incorporados à prática docente como conteúdos a serem transmitidos, os professores agem muitas vezes distantes da realidade vivencial dos alunos, por não terem em conta o contexto da sua prática, como um meio de produção de conhecimentos. Deste modo, o professor não deve limitar-se apenas a conhecer teorias, perspetivas e resultados da investigação (Oliveira, 2002). O professor deve ser capaz de construir soluções adequadas para os diversos aspetos da sua ação profissional. Isso requer, por um lado, não só a capacidade de mobilização e articulação de conhecimentos teóricos, mas também a capacidade de lidar com as situações práticas (Ponte et al., 2000).

Assim, a orientação/supervisão da prática pedagógica deve constituir oportunidades únicas para serem evidenciadas algumas das deficiências da formação científica e pedagógica anteriormente adquiridas, as quais, podem ser tomadas em 
consideração. Logo, os ambientes de aprendizagens criados durante a realização da prática pedagógica, modelados pelo discurso e pelo tipo de tarefas devem favorecer a interação dos antigos e novos significados, permitindo ao aluno incorporar na sua estrutura cognitiva novos significados, que podem substituir ou reforçar os já existentes conscientemente.

\section{PROCEDIMENTOS METODOLÓGICOS}

Foi adotada a abordagem qualitativa de natureza interpretativa e descritiva (Bogdan \& Biklen, 1994). O desenvolvimento do estudo foi inspirado pelos resultados alcançados por Quitembo (2010), a partir do qual selecionou o professor Pedro 3 como o caso de estudo, em virtude de continuar a orientar a prática pedagógica na instituição de formação de professores. A escolha foi propositada uma vez que, a continuidade em lecionar a prática pedagógica, representa o acumular de experiências no processo de orientação da preparação prática dos futuros professores. Para o efeito, sendo a criação de ambientes de aprendizagem na sala de aula pelo professor o foco do estudo, foi selecionado um dos seis praticantes de Pedro, a quem se chamou de Adolfo 4 . $\mathrm{O}$ objetivo foi de se observar as aulas de Adolfo, a partir das quais se analisaria o modo como o professor orienta a preparação prática dos futuros professores. Assim, foram observadas três aulas de Adolfo, seguido do momento de análise de cada uma delas. Na análise da aula, o praticante faz a auto-análise sobre a aula lecionada, seguindo-se os comentários dos observadores (Pedro e outros praticantes) sobre o desenvolvimento da aula, pontos fortes e fracos e possíveis sugestões.

A participação de Pedro, permitiu comparar os procedimentos de orientação registados em Quitembo (2010) e, os registado em 2019 na observação e análise das aulas de Adolfo, como forma de aferir as experiências que transmitem para o desenvolvimento da aprendizagem significativa. Para o efeito, na análise da aula o investigador centrou a atenção nas dimensões que concorrem na definição de ambientes de aprendizagem como suporte para o alcance da aprendizagem significativa, nomeadamente, o tipo de tarefas, o discurso, forma de organização dos alunos.

\footnotetext{
${ }^{3}$ Nome ficticio, diferente da que consta em Quitembo (2010). Pedro manifestou disponibilidade de particpar no estudo

${ }^{4}$ Adolfo- nome ficticio. Manifestou interesse e disponilidade de participar no estudo
} 


\subsection{Resultados}

Conceções da professora sobre ambientes de aprendizagem ${ }^{5}$. O conceito revelado por Pedro sobre ambiente de aprendizagem, se resume na interação que é estabelecida na sala de aula, condicionada ao tipo de tarefas matemáticas, sobretudo as tarefas de índole investigativo: "considero ambientes de aprendizagem a interação entre os alunos em dependência do tipo de tarefas que o professor prepara, principalmente as de investigação". Para ele, estas tarefas exigem do aluno a recolha de elementos complementares para a sua realização: "aquelas que o aluno tem que investigar os caminhos para resolver". Pedro reconhece a importância de ambientes de discussão das tarefas, sobretudo quando os alunos trabalham em grupo. Mas, admite que as discussões e trabalhos em grupos são evidenciadas nas aulas de exercícios, também chamada aula teórico-prática: "é importante que os alunos discutem as tarefas. Exemplo nas aulas prática. Nestas aulas é onde organizo as discussões das tarefas”. Para estas aulas, Pedro concebe a organização de ambientes de interação ou de discussão das tarefas optando pelo sistema de dois grupos: o grupo expositor e o resto da turma, para o qual, a forma de organizar a discussão das tarefas é, normalmente precedida pela preparação das mesmas, principalmente pelo grupo expositor: "há um grupo que prepara a tarefa e outro grupo que faz considerações e critica. As tarefas são preparadas com alguma antecedência". Mas, segundo ele, cabe ao professor o papel de validar os resultados à medida que vai interagindo com cada grupo: "Depois da discussão o professor tem que confirmar os resultados. O professor tem a palavra final".

A formação prática do formando. Na prática letiva de Adolfo (prática pedagógica), constatou-se que a organização e o envolvimento dos alunos seguiu o modelo tradicional, em que cada aluno tem lugar próprio, com envolvimento individual na realização das tarefas. A participação dos alunos nas suas aulas esteve praticamente condicionada às questões colocadas pelo professor, geralmente respondidas em coro, tal como ilustra a descrição de duas das aulas assistidas em 2019:

Quadro 1: Extratos ilustrativos da participação dos alunos nas aulas de Adolfo

\begin{tabular}{|l|l|}
\hline \multicolumn{1}{|c|}{$\mathbf{1}^{\text {a }}$ aula assistida } & \multicolumn{1}{c|}{$\mathbf{3}^{\text {a }}$ aula assistida } \\
\hline Prof: Temos tarefa, pois não? & Prof: todos resolveram a tarefa? \\
Alunos: Não. & Alunos: Sim professor (em coro). \\
Prof: Então, quem se lembra do que tratamos na & $\begin{array}{l}\text { Prof (escreve a tarefa no quadro): Desenha um } \\
\text { aula passada? }\end{array}$ \\
quadrado de 9,5 cm de lado. Ache a sua área. \\
Plunos: Falamos do triângulo (coro).
\end{tabular}

${ }^{5}$ Fonte, tese de Quitembo (2010), pp 260 - 274 
Prof: O que é então um triângulo? O professor indicou um aluno para responder a pergunta.

Aluno Pedro: Triângulo é uma figura que tem três lados.

Prof: Muito bem. Podemos considerar a resposta do vosso colega. Para além da definição do triângulo também aprenderam a calcular a sua área, pois não?

Alunos: Sim (coro)

Prof: Qual é a fórmula que vocês aprenderam? Quem vai escrever no quadro?

Aluna $B: A=\frac{b x h}{2}-$ aluno apenas escreve a fórmula Prof: Ok. Isto quer dizer que a área do triângulo é igual a base vezes altura sobre dois.

Prof: Penso que não há dúvidas?

Alunos: Não, professor (coro).

Prof: Então na aula de hoje vamos resolver exercícios sobre cálculo da área do triângulo. (A seguir escreveu o sumário no quadro: Tema\# Geometria. Sumário: Continuação da aula anterior. Cálculo da área do triângulo.)

Prof: Copiem para os cadernos o que está no quadro (professor escreve o exercício): Desenhar um triangulo que tenha $5 \mathrm{~cm}$ de base e $10 \mathrm{~cm}$ de altura.

Prof: Já copiaram?

Alunos: sim, já (coro)

Prof: Podem resolver, mas sem barulho. Cada um se concentre no seu trabalho, ok?

Alunos: Sim (coro)

Prof: Quem terminar pode avisar o professor. Quem já terminou pode ir resolver no quadro.

\section{Aluno Pedro:}

$$
\begin{array}{ll}
\text { Dados } & \text { Fórmula } \\
b=5 \mathrm{~cm} & A=\frac{b x h}{2} \\
h=10 \mathrm{~cm} & A=(5 \mathrm{~cm} \times 10 \mathrm{~cm}) / 2 \\
& A=50 \mathrm{~cm}^{2} / 2 \\
& A=25 \mathrm{~cm}^{2}
\end{array}
$$

Prof: Alguma dúvida?

Alunos: Não (coro)

Prof: Agora copiem o trabalho de casa (prof. dita e copia no quadro)

Calcule a área de um triângulo que tenha 6,8 $\mathrm{cm}$ de base e 9,2 cm de altura.

Prof: primeiro têm que identificar os dados, após isso devem escrever a fórmula e finalmente fazer a substituição.
Afonso: É preciso desenhar também o quadrado? Prof: Já desenharam todos em casa?

Alunos: Sim professor (coro)

Prof: Afonso apenas achar a área do quadrado.

Afonso (resolve no quadro) - enquanto se resolvia no quadro o professor verificava o trabalho dos alunos nos lugares

Dados

$\mathrm{L}=9,5 \mathrm{~cm}$

$$
\begin{aligned}
& \text { Formula } \\
& A=l x l \\
& A=9,5 \mathrm{~cm} \times 9,5 \mathrm{~cm} \\
& A=90,25 \mathrm{~cm}^{2}
\end{aligned}
$$

Prof: Está correcto, o que Afonso fez?

Alunos: Sim está (coro)

Prof: Ok! Muito bem! Alguém tem dúvidas sobre o exercício que o colega resolveu?

Alunos: Não (em coro)

Prof: Então, na aula de hoje vamos começar com a revisão para a prova. A seguir escreveu o sumário no quadro: Tema\# Geometria. Sumário: Revisão para a prova do professor.

Prof: Copiem para os cadernos o que está no quadro. Depois o professor copia e dita os exercícios

1- Calcule a área de um triângulo de base igual a 3 $\mathrm{cm}$ e de $2 \mathrm{~cm}$ de altura

2- Calcule a área de um quadrado de $10 \mathrm{~cm}$ de lado.

Prof: já copiaram?

Alunos: já sim

Prof: Agora, "mãos a obra", vamos lá resolver os exercícios e sem baralho, está bem?

Alunos: Sim (coro)

Prof: Alguma dúvida sobre o que escreveram?

Alunos: Não (em coro)

Prof: Penso que já terminaram de resolver, pois não?

Alunos: Sim (coro)

Prof: Muito bem. Quem vai resolver o primeiro exercício no quadro?

Prof: Vai a "Joana"

Joana: Dados

$$
\begin{array}{ll}
b=3 \mathrm{~cm} & A=\frac{b \times h}{2} \\
h=2 \mathrm{~cm} & A=(3 \mathrm{~cm} \times 2 \mathrm{~cm}) / 2 \\
& A=6 \mathrm{~cm}^{2} / 2 \\
A=3 \mathrm{~cm}^{2}
\end{array}
$$

Prof: $A$ vossa colega fez bem?

Alunos: Sim (coro)

Prof: Quem não resolveu desta forma passa conforme esta no quadro.

Prof: Agora o "Jorge" vai resolver no quadro o segundo exercício: \# Calcula a área do quadrado de $10 \mathrm{~cm}$ de lado.

$$
\begin{array}{cl}
\text { Jorge: Dados } & \multicolumn{1}{c}{\text { Fórmula }} \\
L=10 \mathrm{~cm} & A=l \times l \\
A=? & A=10 \mathrm{~cm} \times 10 \mathrm{~cm} \\
& A=100 \mathrm{~cm}^{2}
\end{array}
$$

Prof: Ok! Quem não fez assim, passa rápido para o seu caderno. 
As tarefas desenvolvidas na aula estavam direcionadas para a memorização e reprodução do conteúdo, porquanto, não apresentavam desafios para os alunos, senão a aplicação direta da fórmula. O discurso usado por Adolfo, não atentou para a exploração das ideias dos alunos, tão pouco mobilizou os alunos para o trabalho colaborativo, ou que permitisse a exploração de diferentes perceções sobre o conteúdo.

$\mathrm{Na}$ análise do desempenho de Adolfo na ministração das aulas, os observadores debruçaram-se fundamentalmente, sobre a dimensão de conteúdo, no que tange o seu domínio pelo professor (praticante) e dos erros cometidos, com comentários do tipo: "a aula foi boa; os alunos trabalharam os exercícios; o professor foi perguntando e os alunos respondiam; o professor teve algumas dificuldades mas depois superou; apresentou domínio do conteúdo". O tipo de tarefas apresentadas e trabalhadas pelos alunos, o discurso do professor, o envolvimento dos alunos na realização das tarefas, não foram objeto de análise. De igual modo, não se evidenciou questionamentos que exigissem a argumentação com o propósito de explorar as ideias de Adolfo sobre a sua prática por parte de Pedro e de outros observadores, práticas já denunciadas por Quitembo (2010).

Se atendermos que o ambiente de aprendizagem é modelado pela forma de organização dos alunos, o tipo de tarefas propostas e materiais auxiliares, assim como pelo discurso, as aulas assistidas podem-se caraterizar, por um discurso voltado na formulação de questões de natureza fechada, sem exigências na argumentação, tão pouco estimulou a discussão e partilha de ideias. Pelo contrário, o professor exigiu dos alunos o silêncio, e o envolvimento individual na realização das tarefas, caraterísticas próprias de uma aula tradicional.

No entanto, embora o professor orientador revele perspetivas tendentes a criação de ambientes favorecedores da aprendizagem, focalizados no envolvimento dos alunos na realização das tarefas, as suas práticas de orientação do futuro professor revelaram-se contrárias. A ausência de questionamentos pelo professor para os alunos e vice-versa, bem como, entre os alunos sobre as tarefas, o discurso, a forma de organização dos alunos para a aprendizagem e o ensaio de diferentes maneiras de resolver as tarefas, carateriza o modelo tradicional de ensino e aprendizagem. Estas práticas na formação de professores de Matemática traduzem a formação de professores enquadrados no modelo do certo-errado. Este modelo inviabiliza o conhecimento do aluno, suas ideias, suas motivações e o modo de incorporação de novos conhecimentos de forma consciente e ativa. Em suma, os dados revelam que a prática do professor na orientação dos futuros professores, dão primazia aos aspetos de rigor no domínio do conteúdo e das técnicas de 
ensino, em detrimento de outras dimensões que conduzem ao envolvimento do aluno na realização das tarefas e consequentemente, o conhecimento da sua progressão. Daí que, as experiências formativas proporcionadas conservam o modelo tradicional de ensino, que priva os futuros professores na adoção de estratégias variadas que propiciem o envolvimento dos alunos na construção do conhecimento de forma consciente e ativa. Deste modo, se atendermos que os futuros professores tendem a imitar práticas de seus professores, então, as experiências proporcionadas aos futuros professores em relação aos ambientes de aprendizagens enquandram-se no modelo tradicional de ensino, cujas ações não promovem a aprendizagem significativa nos alunos. Ou seja, o centro da sua prática letiva como profissional será atender ao dominio do conteudo, atraves da sua memorização.

\section{CONSIDERAÇÕES FINAIS}

A atividade letiva deve ser desenvolvida em ambientes que propiciem a participação dos alunos, a quem está atribuída a tarefa de construir o conhecimento, e o professor o facilitador dessa construção. Os ambientes criados acabam por representar o aspeto central da construção do conhecimento, uma vez que os mesmos são animados pelas formas de interação estabelecida, moldados pelo discurso e pelas tarefas propostas (Rogers, 2001; Moreira, 2010). Por um lado, é através do discurso que o professor pode perceber o nível de entendimento do conteúdo alcançado pelo aluno, o seu poder de argumentação em defesa das ideias, o que prediz o estádio de capacidade alcançado. Por outro lado, é através das tarefas que o aluno revela as habilidades desenvolvidas na mobilização dos conhecimentos, técnicas e estratégias para dar solução aos desafios explicitos ou implícitos na tarefa, o que prediz o estádio das competências e habilidades alcançadas pelos alunos. No entanto, para a concretização de uma aprendizagem significativa é preciso que o discurso não seja visto separado das tarefas e vice-versa, desenvolvido quer ao nível individual, quer coletivo, pois ambos se complementam. É a partir deles que o professor conhece, acompanha, controla e promove o crescimento do aluno, não só como individualidade singular, mas também como individuo pertencente a um coletivo, que sabe ouvir e respeitar ideias do outro, se sente respeitada e valorizada as suas ideias, ajuda e é ajudado, contribuindo assim, para estimular a auto-confiança dos alunos naquilo que falam e fazem (Moreira, 2006; Santos, 2008). É a partir dos 
ambientes de aprendizagem criados que o professor acompanha e ajuda a realização e desenvolvimento do perfil desejado ao aluno, plasmado no currículo e outros documentos orientadores. É a partir dos ambientes criados na sala de aula onde a avaliação formativa se sobrepõe a avaliação sumativa e o professor põe em prática o seu papel questionador sobre a sua própria prática e a dos seus alunos, com o propósito de melhorar o ensino e a aprendizagem (Paula \& Bida, 2008). Estes aspetos devem constituir o centro da formação prática dos futuros professores, para que eles, as tenham em conta no exercicio da atividade letiva profissional, tendo como base, o questionamento e a argumentação das ideias sobre a realidade da prática letiva (Alarcão \& Roldão, 2008).

Apesar do professor orientador/supervisor manifestar teoricamente, conhecimento e preferência pelos ambientes de interações mutuo entre os intervenientes, com discursos de ajuda e tarefas com algum desafio, a sua prática na orientação dos futuros professores está marcada pela ausência de exigências que promovam tais interações. Por um lado, o discurso aplicado não produz impacto positivo sobre as perceções, as conceções, práticas e na aprendizagem do aluno, pois a ausência de exigências na argumentação dos pontos de vistas, não favorece ao professor conhecer o nível alcançado pelo aluno no saber-fazer e, consequentemente, no poder matemático. Por outro lado, as tarefas apresentadas exigiam a aplicação imediata de fórmulas. De modo geral, o discurso usado estimulou a memorização de técnicas, de conteúdos e estimulou o trabalho individual em detrimento do trabalho colaborativo e interativo. As tarefas apresentadas não desafiaram o raciocínio dos alunos, senão a aplicação imediata de fórmulas. Logo, o ambiente criado mediado pelo discurso e pelas tarefas não favoreceu o desenvolvimento da aprendizagem significativa, porquanto registou-se a implementação de esquemas parametrizados de ensino, adotado e validado pelos especialistas (Ferreira \& Velente, 2020). Contrariamente a apelação de Alarcão e Roldão (2008) a observação e a interação verbal, não constituíram estratégias para um bom clima de colaboração e de encorajamento ao futuro professor para uma reflexão sobre a melhoria da sua prática. Deste modo, o desenvolvimento do modelo tradicional não proporciona testemunhos favorecedores da aprendizagem significativa nos alunos, testemunhos que servirão de base de orientação da sua prática profissional, que encara o aluno como sujeito construtor do conhecimento. 


\section{REFERÊNCIAS}

Alarcão, I. (1994). Ser professor reflexivo. In I. Alarcão (Org). Formação reflexiva de professores. Estratégias de supervisão, (pp. 171-189). Porto: Porto Editora.

Alarcão, I (1989). Para uma revalorização da didáctica. Aprender, 7, 5-8

Alarcão, I e Roldão, M. C. (2008). Supervisão. Um contexto de desenvolvimento profissional dos professores. Portugal: Edições Pedago.

APM (1988). Renovação do Currículo de Matemática. Lisboa: APM

Ausubel, D. P. (1982). A aprendizagem significativa: a teoria de David Ausubel. São Paulo: Moraes.

Bogdan, R. \& Biklen, S. (1994). Investigação Qualitativa em Educação. Uma introdução à teoria e aos métodos. Porto: Porto Editora

Hewson, P. W. (2001). Ensino para mudança conceptual. In: Revista de Educação, Vol. X, $\mathrm{n}^{\circ}$ 2. Departamento de educação da FCUL. Lisboa

Ferreira, J. S. e Valente, W. R (2020). Miguel Aguayo e as mudanças no saber profissional do professor que ensina aritmética. REVEMAT, v.15, (p. 01-18). https://doi.org/10.5007/1981-1322.2020.e66753

Libâneo, J. C. (1998). Organização e Gestão das Escolas - Teoria e Prática. Goiânia: Alternativa.

Klausen, L. S. (2003). Aprendizagem significativa: Um desafio. Disponível em https://educere.bruc.com.br/arquivo/pdf. Acesso em 20 de Março 2019.

Mendes, F., Santarosa, M. C. P. e Camargo, M. (2020). Proposta de uma unidade de ensino potencialmente significativa sobre a teoria de conjuntos. REVEMAT, v. 15 (n. 1) p. 01-23. doi.org/10.5007/1981-1322.2020.e66040

Moreira, M. A. (2010) O que é afinal aprendizagem significativa? Recuperado de http://moreira.if.ufrgs.br/oqueeafinal.pdf

Moreira, M. A. (2006). A teoria da aprendizagem significativa e sua implementação em sala de aula. Brasília: Editora Universidade de Brasília

Moreira, M. A. (2012). Unidades de Ensino Potencialmente Significativas - UEPS. Textos de Apoio ao Professor de Física. Recuperado de:

http://www.if.ufrgs.br/public/tapf/moreira v23 n2.pdf

NCTM (1884). Normas profissionais para o ensino da Matemática. Lisboa: APM e IIE (Original em inglês, publicado em 1989)

Oliveira, A. S. (2002). Formação de professores e criatividade. Amazónida, $n^{\circ}$ 2, (1), (pp. $109-121)$ 
Paula, G. M. C. \& Bida, G. L. (2008). A importância da aprendizagem significativa. Recuperado de http//diaadiaeducacao.pr.gov.br/portals/pde/arquivos/1779-8.pdf

Ponte, J. P.; Januário, C.; Ferreira, I. C. \& Cruz, I (2000). Por uma formação inicial de professores de qualidade. Recuperado de www.meioclique.com/CRUP/Documentos\%20PDF/forminicalqualidade.pff

Ponte, J. P. (1994). Apresentação. In Normas profissionais para o ensino da Matemática. Lisboa: APM e IIE

Ponte, J. P. (1994a). O desenvolvimento profissional do professor de Matemática. Revista Educação e Matemática, $n^{\circ}$ 31. (pp 9 - 12). APM

Ponte, J. P.(1986). Investigação, dinamização pedagógica e formação de professores: três tarefas para a renovação da Educação Matemática. In: Actas do Profmat86. pp 15-45. Portalegre.

Ponte, J. P., Boavida, A. M., Graça, M. \& Abrantes, P. (1997). Didáctica da Matemática. Ministério da Educação: Departamento do ensino secundário. Lisboa, $2^{\mathrm{a}} \quad$ Edição

Ponte, J. P. (1999). Didácticas específicas e construção do conhecimento profissional. In Acta do IV Congresso da SPCE. Investigar e formar em educação. pp 59-72. Porto: SPCE

Precatado, A., Lopes, A.V., Baeta, A., Loureiro, C., Ferreira, E., Guimarães, H.M.,..., \& Abrantes, P. (1998). Matemática 2001 - Recomendações para o Ensino e Aprendizagem da Matemática. Lisboa: APM \& IIE

Quitembo, A. D. J. (2010). A formação de professores de Matemática no Instituto Superior de Ciências de Educação em Benguela - Angola. Um estudo sobre o seu desenvolvimento. Lisboa: APM. Colecção Teses.

Rogers, C. R. (2001). Tornar-se pessoa. 5. Ed São Paulo: Martins

Santos, J. C. F. (2008). Aprendizagem Significativa: modalidades de aprendizagem e o papel do professor. Porto Alegre: Mediação.

Serrazina, L. (2002). A formação para o ensino da Matemática na educação pré - escolar e no $1^{\circ}$ ciclo do ensino básico. Porto: Porto Editora

Vale, M. I. P. (2000). Didáctica da Matemática e formação inicial de professores num contexto de resolução de problemas e de Materiais manipuláveis. Lisboa: APM

Valente, W. R. (2017). Os saberes para ensinar matemática e a profissionalização do educador matemático. Revista Diálogo Educacional, v.17,(51), pp. 207-222 


\title{
NOTAS
}

\section{TÍTULO DA OBRA}

Ambientes de aprendizagens versus aprendizagem significativa. Uma análise de práticas desenvolvidas na formação de professores de Matemática em Benguela-Angola.

\author{
Alberto Domingos Jacinto Quitembo \\ Professor Associado \\ Instituto Superior de Ciências de Educação da Universidade Katyavala Bwila, Benguela, Angola \\ jquitembo50@gmail.com \\ (1) http://orcid.org/0000-0002-7724-8886
}

Endereço de correspondência do principal autor

Rua de Moçambique 7, $9^{\circ}$ esquerdo, Benguela - Angola

\section{AGRADECIMENTOS}

Não se aplica.

\section{CONTRIBUIÇÃO DE AUTORIA}

Concepção e elaboração do manuscrito: A. D. J. Quitembo

Coleta de dados: A. D. J. Quitembo

Análise de dados: A. D. J. Quitembo

Discussão dos resultados: A. D. J. Quitembo

\section{CONJUNTO DE DADOS DE PESQUISA}

O conjunto de dados que dá suporte aos resultados deste estudo não está disponível publicamente, exceto dados de Pedro (concepções) disponível em Quitembo (2010).

\section{FINANCIAMENTO}

Não se aplica.

\section{CONSENTIMENTO DE USO DE IMAGEM}

Não se aplica.

\section{APROVAÇÃO DE COMITÊ DE ÉTICA EM PESQUISA \\ Não se aplica.}

\section{CONFLITO DE INTERESSES}

Não se aplica.

\section{LICENÇA DE USO}

Os autores cedem à Revemat os direitos exclusivos de primeira publicação, com o trabalho simultaneamente licenciado sob a Licença Creative Commons Attribution (CC BY) 4.0 International. Estra licença permite que terceiros remixem, adaptem e criem a partir do trabalho publicado, atribuindo o devido crédito de autoria e publicação inicial neste periódico. Os autores têm autorização para assumir contratos adicionais separadamente, para distribuição não exclusiva da versão do trabalho publicada neste periódico (ex.: publicar em repositório institucional, em site pessoal, publicar uma tradução, ou como capítulo de livro), com reconhecimento de autoria e publicação inicial neste periódico.

\section{PUBLISHER}

Universidade Federal de Santa Catarina. Grupo de Pesquisa em Epistemologia e Ensino de Matemática (GPEEM). Publicação no Portal de Periódicos UFSC. As ideias expressadas neste artigo são de responsabilidade de seus autores, não representando, necessariamente, a opinião dos editores ou da universidade.

\section{EDITOR}

Méricles Thadeu Moretti e Rosilene Beatriz Machado

HISTÓRICO - uso exclusivo da revista

Recebido em: 13-05-2020 - Aprovado em: 19-07-2020 